\title{
Corrigendum
}

\section{Corrigendum to "Mistaken Diabetic Ulcers: A Case of Bilateral Foot Verrucous Carcinoma"}

\author{
Vanessa Di Palma, ${ }^{1}$ Jill P. Stone $\mathbb{D}^{\circ},{ }^{2}$ Andrew Schell, ${ }^{3}$ and Jeffrey C. Dawes ${ }^{2}$ \\ ${ }^{1}$ Department of Obstetrics and Gynecology, University of Calgary, Calgary, AB, Canada \\ ${ }^{2}$ Division of Plastic Surgery, Department of Surgery, University of Calgary, Calgary, AB, Canada \\ ${ }^{3}$ Department of Pathology \& Laboratory Medicine, University of Calgary and Calgary Laboratory Services, Calgary, AB, Canada \\ Correspondence should be addressed to Jill P. Stone; jstone@ucalgary.ca
}

Received 13 March 2018; Accepted 15 March 2018; Published 15 April 2018

Copyright ( 2018 Vanessa Di Palma et al. This is an open access article distributed under the Creative Commons Attribution License, which permits unrestricted use, distribution, and reproduction in any medium, provided the original work is properly cited.

In the article titled "Mistaken Diabetic Ulcers: A Case of Bilateral Foot Verrucous Carcinoma" [1], the first affiliation is incorrectly linked to the fourth author. The corrected affiliation is shown above.

\section{References}

[1] V. Di Palma, J. P. Stone, A. Schell, and J. C. Dawes, "Mistaken Diabetic Ulcers: A Case of Bilateral Foot Verrucous Carcinoma," Case Reports in Dermatological Medicine, vol. 2018, Article ID 4192657, 3 pages, 2018. 


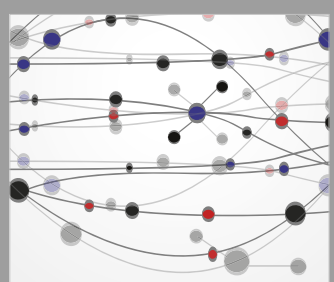

The Scientific World Journal
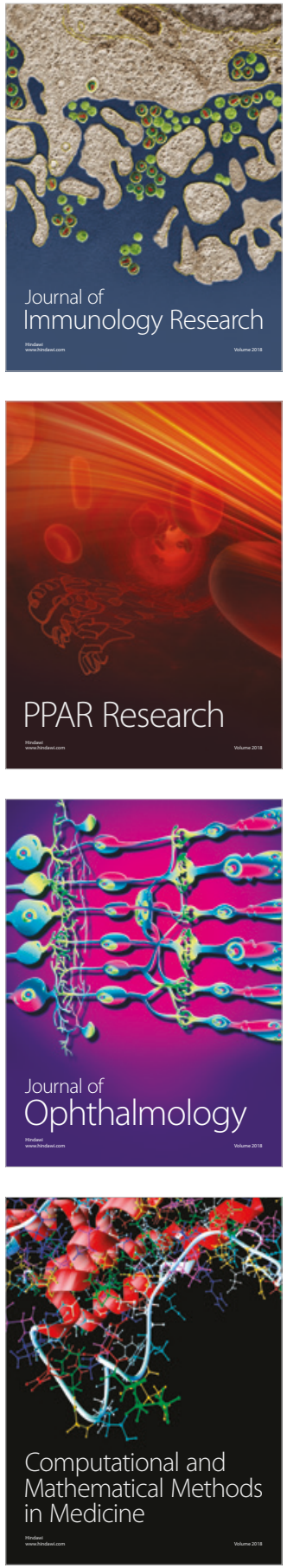

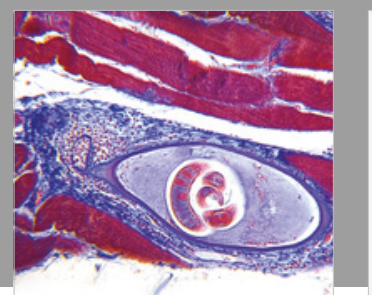

Gastroenterology Research and Practice

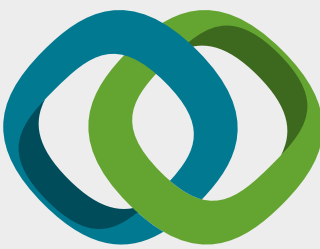

\section{Hindawi}

Submit your manuscripts at

www.hindawi.com
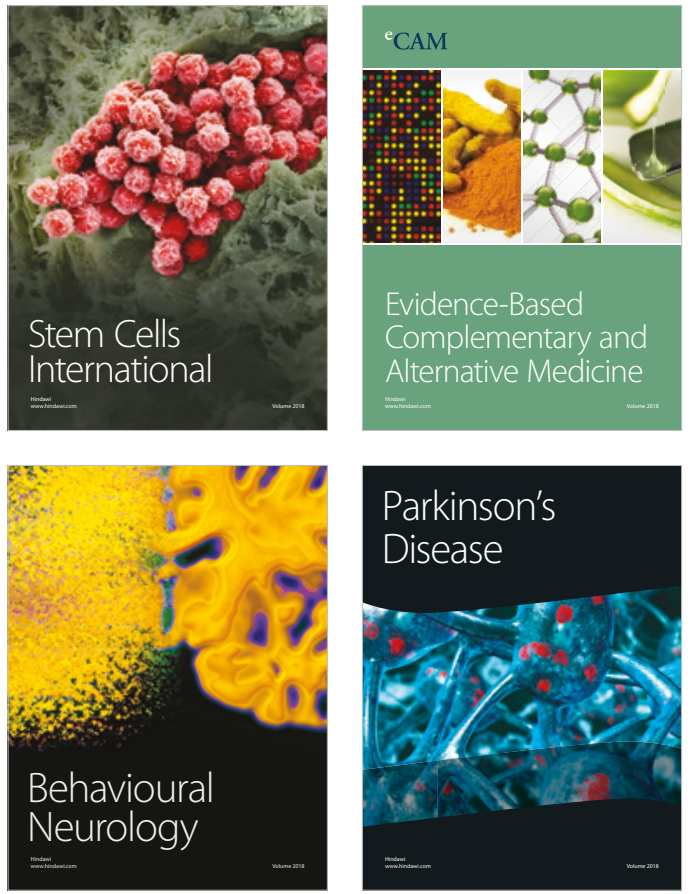

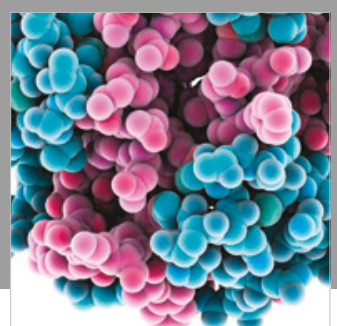

ournal of

Diabetes Research

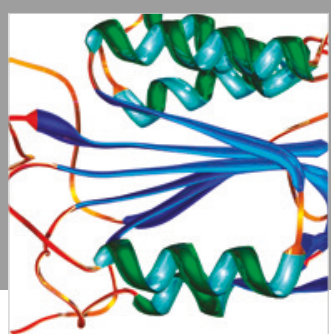

Disease Markers
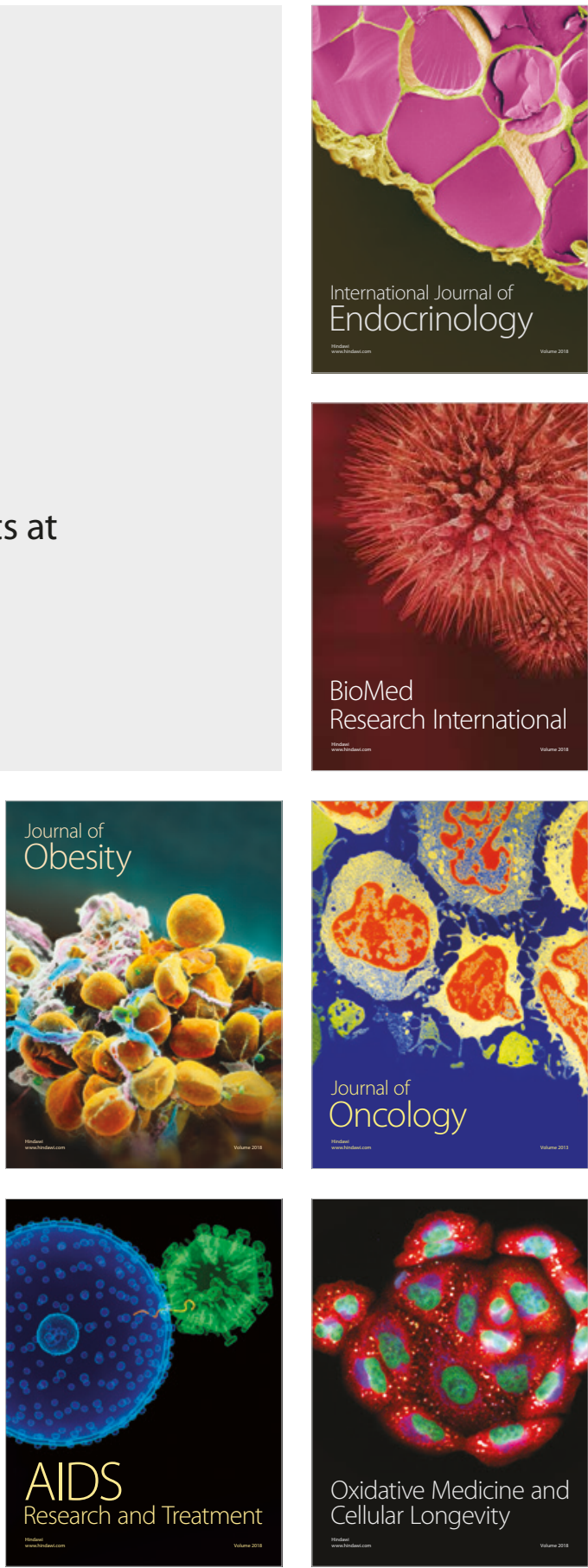